\title{
Reduced Immobility in the Forced Swim Test in Mice with a Targeted Deletion of the Leukemia Inhibitory Factor (LIF) Gene
}

\author{
Robert N Pechnick*,', Vera M Chesnokova², Anastasia Kariagina', Shannon Price', Catherine J Bresee' and \\ Russell E Poland ${ }^{1,3}$ \\ 'Department of Psychiatry and Mental Health, Cedars-Sinai Medical Center, Los Angeles, CA, USA; ${ }^{2}$ Department of Endocrinology, Cedars-Sinai \\ Medical Center, Los Angeles, CA, USA; ${ }^{3}$ Brain Research Institute, David Geffen School of Medicine, UCLA, Los Angeles, CA, USA
}

\begin{abstract}
Cytokines are a large and diverse group of polypeptides that are rapidly released in response to tissue injury, infection, and inflammation. Besides their effects in the periphery, cytokines also affect the central nervous system (CNS). There has been increasing interest in the potential role of cytokines in the behavioral features of depressive disorders. One cytokine that might be a candidate for a role in the etiology of depression is leukemia inhibitory factor (LIF). LIF mRNA has been detected in the hypothalamus, hippocampus, amygdala, cerebellum, cerebral cortex, and basal forebrain nuclei. The role of LIF in the CNS has not been fully elucidated. Based upon the hypothesis that cytokines might have a role in depression, the present study characterized the behavior of mice with a targeted disruption of the LIF gene (LIF knockouts) in the forced swim test, an animal model used to measure depressive-like behavior and the response to antidepressants. It was found that LIF knockout mice show reduced immobility in the forced swim test, suggesting that LIF might have a potential role in the etiology of some forms of depression.

Neuropsychopharmacology (2004) 29, 770-776, advance online publication, I 8 February 2004; doi: I 0. I038/sj.npp. I 300402
\end{abstract}

Keywords: cytokine; stress; gene deletion; animal models; inflammation

\section{INTRODUCTION}

Cytokines are a large and diverse group of polypeptides that have pleiotropic actions, including the regulation of metabolism, growth, and differentiation. They are rapidly released in response to tissue injury, infection, and inflammation. Although cytokines generally act on hemopoietic or immune cells, they also serve as growth and differentiation factors for other cell types. Cytokines commonly behave as paracrine or autocrine cell regulators, mediating adjacent cell functions. However, they can act as classic endocrine secretions, emanating from proximal tissues, traversing the circulation, and impacting a distal target (Reichlin, 1999).

In addition to their effects in the periphery, cytokines affect the central nervous system (CNS). There are four well-established mechanisms by which cytokines can enter

*Correspondence: RN Pechnick, Department of Psychiatry and Mental Health, Cedars-Sinai Medical Center, 8730 Alden Drive, Los Angeles, CA 90048, USA, Tel: + I 310423 6206, Fax: + I 3104230888 ,

E-mail: pechnickr@cshs.org

Received 22 May 2003; revised 03 December 2003; accepted 06 January 2004

Online publication: 8 January 2004 at http://www.acnp.org/citations/ Npp0 I080403235/default.pdf the brain or affect CNS activity: (1) disruption and traversing through the blood-brain barrier; (2) brain penetration through circumventricular organs (central sites that have capillaries with open junctions and abundant fenestrations); (3) action on afferent peripheral nerves that signal the brain; and (4) de novo CNS synthesis (Licinio and Wong, 1997). The constitutive expression of cytokines and cytokine receptors occurs on most cell types throughout the brain. Cytokines affect neurotransmission, alter synaptic plasticity, and $\mathrm{Ca}^{2+}$ signaling (Rudge et al, 1996; Vitkovic et al, 2000). Thus, cytokines are neuromodulators in addition to being inflammatory mediators (Vitkovic et al, 2000). These findings suggest that cytokines could be involved in centrally mediated processes, and might play a role in behavioral and physiological responses besides inflammation (Suzuki et al, 1996; Chesnokova et al, 1998).

There has been increasing interest in the potential role of the immune system and cytokines in the behavioral features of depressive disorders (Kent et al, 1992; Connor and Leonard, 1998; Miller, 1998; Dantzer et al, 1999; Yirmiya et al, 1999; Leonard, 2001; Konsman et al, 2002). Symptoms of depression are exceedingly common in a wide range of inflammatory and autoimmune diseases. In addition, some patients with major depression have alterations in immune 
function. Preclinical studies have shown that interleukin-1 (IL-1) or lipopolysaccharide (LPS), which induces the synthesis and release of many cytokines, produce a behavioral syndrome known as 'sickness behavior'. This syndrome shares many features in common with major depression, including anhedonia, listlessness, altered sleep patterns, increased hypothalamo-pituitary-adrenal (HPA) axis activity, reduced appetite, and social withdrawal (Bluthe et al, 1997; Connor and Leonard, 1998; Miller, 1998; Licinio and Wong, 1999; Wichers and Maes, 2002). These symptoms are largely attenuated by the prior administration of the IL-1 antagonist IL-10 (Bluthe et al, 1999). The preclinical observations have been confirmed in humans. For example, recent studies have shown that in some cases major depression is accompanied by increased synthesis and release of circulating proinflammatory cytokines ((IL-1, IL-6, and tumor necrosis factor (TNF)) (Connor and Leonard, 1998; Maes, 1999; Miller, 1998). Furthermore, administering LPS, interferon- $\gamma$, INF- $\gamma$, or IL-2 to humans elicits symptoms of depression (Yirmiya et al, 2000; Wichers and Maes, 2002).

Another cytokine that might play a role in the etiology of depression is leukemia inhibitory factor (LIF). LIF is a member of the common IL-6 cytokine family, comprised of IL-6, oncostatin M, IL-11, ciliary neurotropic factor, and cardiotropin. All cytokines in this family interact with a common gp130 receptor subunit, and utilize the JAK-STAT signaling pathway. LIF initially was noted for its ability to induce differentiation of murine M1 leukemia cells. Subsequent studies revealed that it has diverse biological activity (Auernhammer and Melmed, 2000). LIF and LIF receptors are constitutively expressed in human pituitary cells (Akita et al, 1997) and in murine hypothalamus and pituitary (Auernhammer and Melmed, 2000). LIF, along with corticotropin-releasing hormone $(\mathrm{CRH})$, stimulates ACTH secretion in response to emotional and inflammatory stress (Chesnokova et al, 1998; Auernhammer et al, 1998). LIF is highly induced in the hypothalamus and pituitary in response to inflammation (Chesnokova and Melmed, 2000; Chesnokova et al, 2002), and it maintains a prolonged and sustained activation of the HPA axis under chronic inflammatory challenge. Thus, in addition to $\mathrm{CRH}$, LIF mediates HPA axis activity.

LIF mRNA has been detected in the hypothalamus, hippocampus, amygdala, cerebellum, cerebral cortex, and basal forebrain nuclei (Lemke et al, 1996; Gadient et al, 1998; Auernhammer and Melmed, 2000; Chesnokova et al, unpublished data). However, the role of LIF in the CNS has not been fully elucidated. LIF is required for neuronal survival after injury (Sugiura et al, 2000), and prevents oligodendrocyte death in animal models of multiple sclerosis (Butzkueven et al, 2002). In vitro, LIF induces a switch from the noradrenergic to the cholinergic neurotransmitter phenotype in sympathetic neurons (Cervini et al, 1994). Interestingly, tyrosine hydroxylase mRNA is enhanced in neuronal cultures incubated with anti-LIF antibodies, suggesting that LIF might be involved in the regulation of noradrenergic systems (Cheng and Patterson, 1997).

Based upon the hypothesis that proinflammatory cytokines might be involved in the etiology of depression, it was decided to study the behavior of mice with a targeted disruption of the LIF gene (LIF knockouts) in the forced swim test, an animal model used to measure depressive-like behavior and the response to antidepressants (Porsolt et al, 1977a,b; Borsini and Meli, 1988). In order to further characterize the mice, locomotor activity was measured in the open field test, and their behavior was assessed in the elevated plus maze, an animal model of anxiety (Dawson and Tricklebank, 1995).

\section{MATERIALS AND METHODS}

\section{Animals}

Adult male and female mice with a disrupted LIF gene (LIFKO mice) and their wild-type (WT) counterparts were used in the experiments. LIFKO mice initially were generated by Dr Stewart (Roche Institute of molecular biology, Roche Research center, Nutley, NJ) on mice with a C57Bl/6j and DBA/2 hybrid background (B6D2F1) (Stewart et al, 1992). The mice used for the present experiments were bred and raised in our vivarium. The original breeding pairs were backcrossed to one of the parental genotypes (C57BL/ 6j) at least five times prior to using them in our experiments. Thus, genetic background of resulting LIFKO mice was comprised of more than $98 \%$ of $\mathrm{C} 57 \mathrm{Bl} / 6 \mathrm{j}$ genotype. For the experiments, LIFKO and WT mice were obtained from heterozygous matings. All pups were genotyped by tail biopsies at 3 weeks of age. For the PCRbased DNA analysis, the tip of the tail was cut while the mice were under isoflurane-induced anesthesia. DNA was extracted using a genomic DNA extraction system (Purigene; Genetech, Research Triangle Place, NC). The sequences of primers and conditions used for PCR analysis have been described previously (Chesnokova et al, 1998). After screening, the mice were separated by sex and group housed. Animals were maintained on a 14:10 light-dark cycle with lights on at 0700 with food and water available ad libitum. All experiments were run between 0900 and 1300 in order to minimize the effect of circadian rhythms. The level of illumination in the rooms during experimental testing was 325 lumens.

\section{Forced Swim Test}

The forced swim test was carried out using a procedure modified from the original report by Porsolt et al (1977a). The mice were individually placed into a glass cylinder (25 cm height, $10 \mathrm{~cm}$ diameter) containing $8 \mathrm{~cm}$ of water maintained at $22-24^{\circ} \mathrm{C}$. Every $30 \mathrm{~s}$ for a total of $6 \mathrm{~min}$ the mice were rated for immobility, defined as the absence of active, escape-oriented behaviors such as swimming, jumping, rearing, sniffing, or diving. At each time point the mice were observed for $10 \mathrm{~s}$ and immobility was recorded as being present or absent. Any mouse appearing to have difficulty keeping its head above water was removed from the cylinder and deleted from the study. The rater was blind to the experimental treatment. The procedure has been validated in our laboratory by showing the treatment with imipramine dramatically decreases immobility in WT, female mice (Pechnick et al, unpublished data). 


\section{Open Field Test}

The open field test was used to measure spontaneous locomotor activity. The Open Field apparatus (San Diego Instruments, San Diego, CA) was comprised of open topped, clear Plexiglas boxes, measuring $16^{\prime \prime} \times 16^{\prime \prime}$ and $15^{\prime \prime}$ high. On the day of the experiments the subjects were loaded into transfer cages and brought into the experimental room. They remained in the transfer cages in the experimental room for $30 \mathrm{~min}$, after which each subject is placed into the center of the Plexiglas boxes. Both central and peripheral beam breaks (locomotion) were recorded in $5 \mathrm{~min}$ bins for $60 \mathrm{~min}$. The central zone was defined as a $12^{\prime \prime} \times 12^{\prime \prime}$ region in the center of the box.

\section{Elevated Plus-Maze}

The elevated plus maze consisted of two open $\left(2^{\prime \prime} \times 12^{\prime \prime}\right)$ and two darkened, closed arms $\left(2^{\prime \prime} \times 12^{\prime \prime}\right)$ emanating from a common central platform $\left(2^{\prime \prime} \times 2^{\prime \prime}\right)$ to form a plus shape. Walls $\left(6^{\prime \prime}\right)$ isolated the closed arms. The entire apparatus was raised $23 \mathrm{~cm}$ above its base, and a light was placed above the maze. Testing commenced by placing a mouse on the central platform, facing an open arm. A $5 \mathrm{~min}$ observation period was used, during which the following data were recorded: number of open arm entries; total arm entries (open and closed); and time spent in the open arms.

\section{Statistical Analyses}

For the forced swim test, the number of time points where immobility was scored during the last $4 \mathrm{~min}$ of the experimental session were summed for each subject (Porsolt et al, 1977a). The summed scores were analyzed by two-way ANOVA (strain $\times$ sex), followed by one-way ANOVA for each sex. For locomotor activity, total beam breaks across the $60 \mathrm{~min}$ session were summed for each subject. The summed scores were analyzed by two-way ANOVA. For the elevated plus maze, the number of open and closed arm entries, the proportion of open to total arm entries, and the time spent in the open arms were analyzed by two-way ANOVA, followed by one-way and Scheffe's tests for comparisons between treatment groups. A criterion of $p<0.05$ was set for the rejection of the null hypothesis.

\section{RESULTS}

No mice were deleted from the study. In the forced swim test, there were significant strain effects $(F(1,58)=14.4$; $p<0.01)$, but neither the sex $(\mathrm{F}(1,58)=4.0 ; p=0.05)$ nor the interaction $(\mathrm{F}(1,58)=0.09 ; p=0.34)$ effects were statistically significant. Both the male (Figure 1a) and female (Figure 1b) LIFKO mice showed significantly less immobility compared to the WT mice $(\mathrm{F}(1,18)=15.8 ; p<0.01$; and $\mathrm{F}(1,40)=5.2 ; p=0.03$, respectively).

In the open field test, there were no significant strain $(\mathrm{F}(1,61))=0.33 ; p=0.57)$ or $\operatorname{sex}(\mathrm{F}(1,61)=0.48 ; p=0.49)$ differences in total locomotor activity between the WT and LIFKO mice (Figure 2). In addition, there were no significant strain $(\mathrm{F}(1,61=3.47 ; p=0.07) \quad$ or $\quad$ sex $(\mathrm{F}(1,61)=0.001 ; p=0.98)$ differences in the proportion of

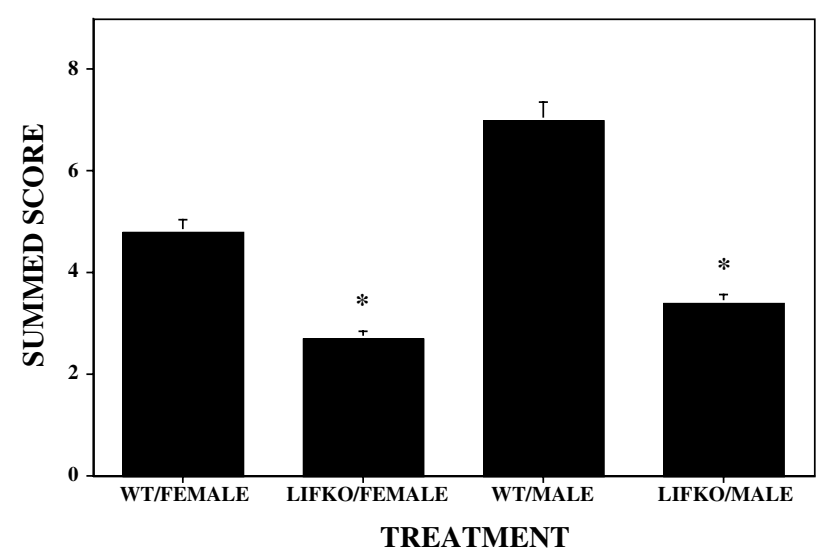

Figure I Summed immobility score for male and female WT and LIFKO mice. The mice were individually placed into a glass cylinder containing water. The number of time points where immobility was scored during the last 4 min of the experimental session were summed for each subject Both the male and female LIFKO mice showed significantly less immobility compared to the WT mice. N/group: WT/female, 20; LIFKO/female, 22; WT/Male 9; LIFKO/Male, II.

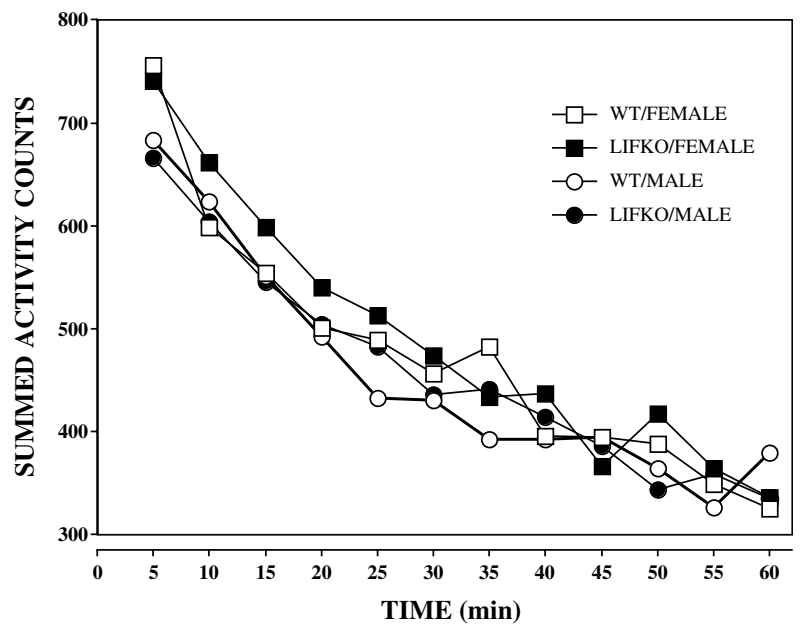

Figure 2 Mean number of total activity counts in the open field test. Beam breaks (locomotion) are recorded in $5 \mathrm{~min}$ bins for $60 \mathrm{~min}$. There were no significant differences among treatment groups. N/group: WT/ female, 16; LIFKO/female, I9; WT/Male, I4; LIFKO/Male, I6. SEM $\leqslant 54$ counts.

locomotor activity in the central $v s$ the peripheral areas of the boxes (Figure 3 ).

In the elevated plus maze (Figures $4 \mathrm{a}-\mathrm{c}$ ), there were no statistically significant strain differences in the number of open arm entries $(\mathrm{F}(1,49)=3.223 ; p=0.08)$, time in the open arms $(\mathrm{F}(1,49)=2.620 ; p=0.11)$, or the number of total arm entries $(\mathrm{F}(1,49)=3.882 ; p=0.05)$. There was a significant sex difference in the number of total arm entries $(\mathrm{F}(1,49)=12.866 ; p<0.01)$, but not in the number of open arm entries $(\mathrm{F}(1,49)=3.735 ; p=0.06)$ or the time in the open arms $(F(1,49)=0.001 ; p=0.98)$. There were statistically significant interaction effects for the number of open arm entries $(\mathrm{F}(1,49)=14.929 ; p<0.01)$ and time in the open 


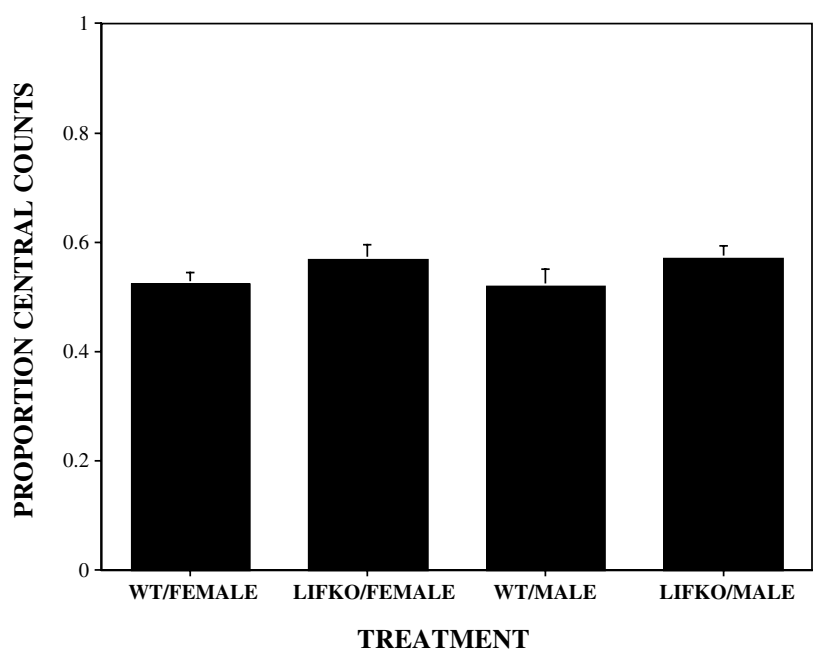

Figure 3 Mean proportion of activity counts in the central portion of the test chamber. The number of beam breaks (locomotion) in the central portion of the test chamber was divided by the total number of beam breaks (central plus peripheral). N/group: WT/female, I6; LIFKO/female, 19; WT/Male, I4; LIFKO/Male, 16.

arms $(\mathrm{F}(1,49)=5.914 ; p=0.02)$, but not for the number of total arm entries $(\mathrm{F}(1,49)=3.845 ; p=0.06)$. Individual comparisons indicate that the WT male mice had fewer open arm entries, spent less time in the open arms, and had fewer total arm entries than the LIFKO male mice. In addition, the WT male mice had fewer open arm entries and fewer total arm entries than the WT female mice.

\section{DISCUSSION}

Little is know about behavior or physiology in LIF knockout mice. The data indicate that the LIFKO mice show less immobility in the forced swim test. One possible explanation for this finding is that the LIFKO mice are hyperactive compared to the WT mice. The data from the open field test demonstrate that there are no differences in locomotor activity between the LIFKO and WT mice. In the elevated plus maze, the total number of entries can be used as an indicator of general activity. Although the male LIFKO mice had significantly more total arm entries than the male WT mice, there were no significant differences between the female LIFKO and WT mice. As both sexes showed the strain difference in the forced swim test, this suggests that hyperactivity per se is not responsible for the decreased immobility in the forced swim test. However, the mechanisms underlying the decreased immobility need not be the same in both sexes. A second possible explanation for less immobility in the LIFKO mice is that they showed higher levels of fear or anxiety. Such fear could be reflected by more swimming (ie less immobility). The data from the elevated plus maze show that the LIFKO mice do not have higher levels of anxiety. In fact, the male LIFKO mice show reduced levels of anxiety, as measured by increased open arm entries and more time spent in the open arms. Reduced activity in the central component of the boxes in the open field test can be used as an indicator of increased fearfulness. As there were not significant strain differences,
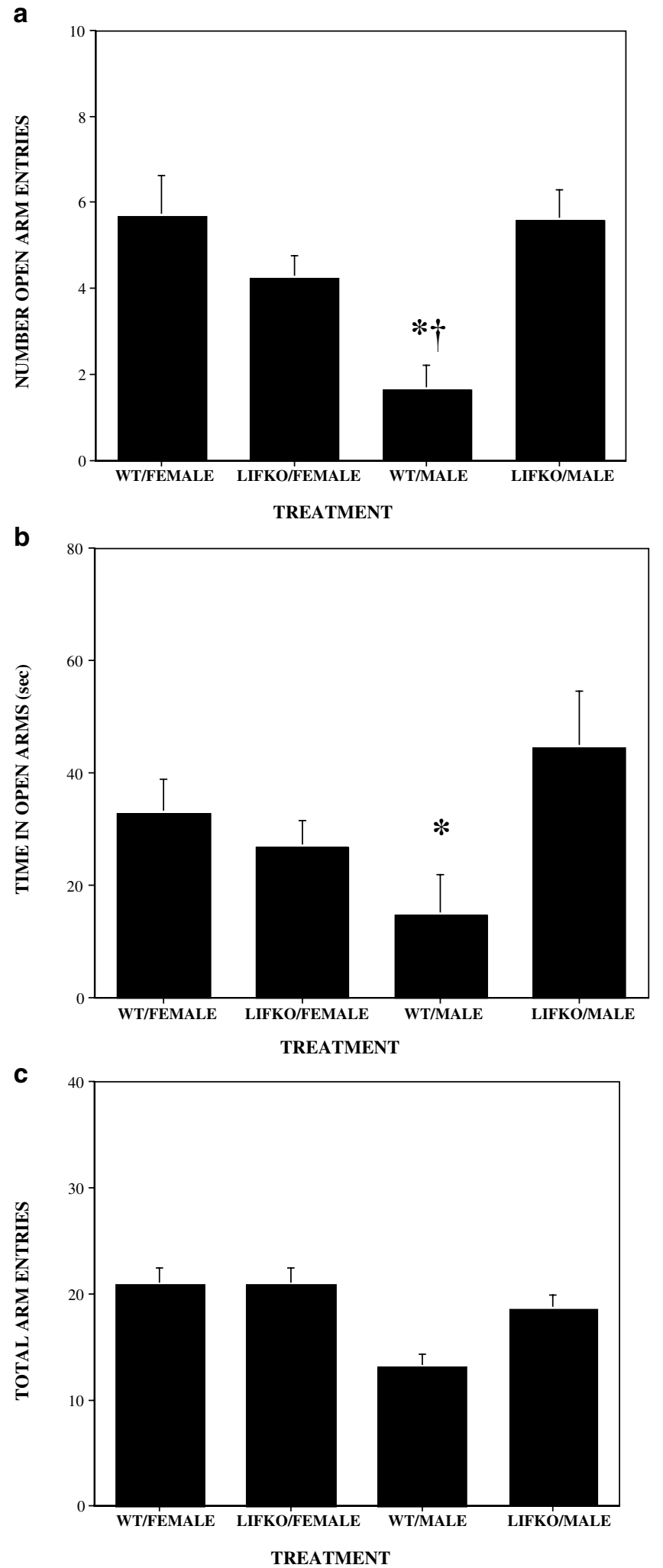

Figure 4 The number of open arm entries (a), time in the open arms (b), and total arm entries (c) in the elevated plus maze. A 5 min observation period was used. * Significantly different from LIFKO males; † significantly different from WT females. N/group: WT/female, I2; LIFKO/female, I3; WT/Male, I4; LIFKO/Male, I4. 
this further supports the contention that the LIFKO mice do not show increased fear.

Taken together, the results suggest that the decreased immobility found in the LIFKO mice is not a consequence of hyperactivity or increased fearfulness, but could be due to antidepressant-like behavior as measured by the forced swim test. Yamada et al (2000) examined tumor TNF- $\alpha$ knockout mice, and found reduced immobility in the forced swim test. However, they also found less time spent in the open arms in the elevated plus maze, which led Yamada et al (2000) to conclude that the TNF- $\alpha$ knockout mice were in a state of increased anxiety and the reduced immobility due to 'inappropriate coping responses', rather than reduced depression. As the absence of LIF was associated with antidepressant-like behavior, then it is possible that increased levels of LIF could lead to increased immobility in the forced swim test. LIF is expressed in the hypothalamus (Chesnokova and Melmed, 2000), amygdala, and hippocampus (Chesnokova et al, unpublished data), regions of the CNS that are associated with depressive and stressrelated behaviors as well as in antidepressant response (Manji et al, 2001; Davidson et al, 2002). Thus, LIF might be involved in the etiology of some forms of depression.

There are a number of potential mechanisms whereby LIF and other cytokines could produce depressive behavior. Although little is known about the effects of LIF on neurotransmission within the CNS, other cytokines affect neurotransmitters that have been implicated in the etiology of depression (eg serotonin and norepinephrine). For example, some cytokines have profound effects on serotonergic neurotransmission (Heyes et al, 1997; Cunningham and de Souza, 1993; Ramamoorthy et al, 1995; Barkhudaryan and Dunn, 1999; Hayley et al, 1999; Mossner and Lesch, 1998). Cytokines also affect noradrenergic neurotransmission (Leonard, 2001; Dunn et al, 1999). Cytokine-mediated dysregulation of these monoaminergic systems could be involved in depressive symptomatology.

Dysregulation of the HPA axis is observed in some depressed patients (Gertsik and Poland, 2004). As LIF (Chesnokova et al, 1998, 2002; Chesnokova and Melmed, 2000) and other cytokines (Turnbull and Rivier, 1999) exert important changes in the activity of the HPA axis, it is conceivable that some of the behavioral effects of LIF and other cytokines might be mediated through the HPA axis. Although cytokines usually are thought of as immunomodulators, they also are rapidly expressed in the CNS in response to nonimmunologic stressors (Shintani et al, 1995; Shizuya et al, 1998). Thus, the HPA response to stressors might be modified by changes in the release of cytokines. We have found that LIFKO mice demonstrate a reduced HPA axis response to both emotional and inflammatory stress (Chesnokova et al, 1998; Auernhammer et al, 1998). Furthermore, LIF stimulates glucocorticoid receptor translocation and inhibits hormone-induced glucocorticoid receptor-mediated gene transcription (Chesnokova et al, unpublished data), thus producing glucocorticoid resistance, which is a pathophysiologic phenotype of depression. Therefore, it is possible that some of the behavioral effects of LIF are due to changes in the function of the HPA axis.

$\mathrm{CRH}$ has been implicated in the etiology of depression (Nemeroff, 1996). Although multiple aspects of the HPA axis appear to be dysregulated in depression, a primary upregulation of CRH secretion can account for most, if not all, aspects of the endocrine abnormalities. There are clearcut interactions between LIF and CRH (Bousquet et al, 1997). It is possible that the reduced immobility of the LIFKO mice in the forced swim test is secondary to changes in CRH. However, hypothalamic CRH mRNA expression is not reduced, but slightly elevated in LIFKO mice. Furthermore, basal corticosterone levels are not different between LIKKO and WT mice (Chesnokova et al, 1998). These findings suggest that the reduced immobility in the forced swim test in the LIFKO mice is not due to a decrease in central CRH expression.

Although that data suggest that LIF might be involved in the etiology of depression, it is not possible to establish conclusively a relation between the LIF gene and depression based upon the small number of tests conducted. More tests (eg tail suspension and learned helplessness) will need to be conducted. Furthermore, there are limitations regarding the interpretation of studies evaluating the phenotype of a knockout mouse. First, the genetic mutation has been present from the time of conception throughout development, making it difficult to distinguished phenotypic changes due to the mutation itself from the changes caused by alterations that take place during development. For example, LIFKO mice might be exposed to lower concentrations of glucocorticoids during development, which might contribute to their behavioral phenotype. Second, if a gene is expressed in different tissues where it might have different functions, or at different times, its global inactivation might have multiple consequences. Third, the genetic background on which the mutation is placed can affect the phenotypic expression of the knockout. Therefore, a knockout animal is much more complex than simply a animal lacking a single gene, and interpretation of data from experiments using this approach must take into consideration these potential confounds.

In summary, the results of the present study show that mice lacking LIF have reduced immobility in the forced swim test. The decreased immobility found in the LIFKO mice is not a consequence of hyperactivity or increased fearfulness. These findings suggest that LIF might have a potential role in the etiology of some forms of depression, and warrant further studies on the behavioral effects of LIF and its role in CNS function.

\section{ACKNOWLEDGEMENTS}

We would like to thank Dr Roger D Porsolt for helpful suggestions, Dr Allan C Collins for the gift of the elevated plus maze, and Dr Jeanne M Wehner for helpful converstations. Partially supported by NIH Grant R29-DK54862 and a NARSAD Young Investigator Award to VMC.

\section{REFERENCES}

Akita S, Readhead C, Stefaneanu L, Fine J, Tenpanaru-Sermesilu A, Kovacs K, et al. (1997). Pituitary-directed leukemia inhibitory factor transgene forms Rathke's cleft cysts and impairs adult pituitary function. J Clin Invest 99: 2462-2469.

Auernhammer C, Chesnokova V, Melmed S (1998). Leukemia inhibitory factor modulates interleukin- $1 \beta$-induced activation of 
the hypothalamo-pituitary-adrenal axis. Endocrinology 139: 2201-2208.

Auernhammer CJ, Melmed S (2000). Leukemia-inhibitory factorneuroimmune modulator of endocrine function. Endocrine Rev 21: 313-345.

Barkhudaryan N, Dunn AJ (1999). Molecular mechanisms of actions of interleukin- 6 on the brain, with special reference to serotonin and the hypothalamo-pituitary-adrenocortical axis. Neurochem Res 24: 1169-1180.

Bluthe RM, Castanon N, Pousset F, Bristow A, Ball C, Lestage J et al (1999). Central injection of IL-10 antagonizes the behavioural effects of lipopolysaccharide in rats. Psychoneuroendocrinology 24: 301-311.

Bluthe RM, Dantzer R, Kelley KW (1997). Central mediation of the effects of interleukin-1 on social exploration and body weight in mice. Psychoneuroendocrinology 22: 1-11.

Borsini F, Meli A (1988). Is the forced swimming test a suitable model for revealing antidepressant activity? Psychopharmacology 94: 147-160.

Bousquet C, Ray DW, Melmed S (1997). A common proopiomelanocortin-binding element mediates leukemia inhibitory factor and corticotropin-releasing hormone transcriptional synergy. Biol Chem 272: 10551-10557.

Butzkueven H, Zhang JG, Soilu-Hanninen M, Hochrein H, Chionh F, Shipham KA et al (2002). LIF receptor signaling limits immune-mediated demyelination by enhancing oligodendrocyte survival. Nat Med 8: 613-619.

Cervini R, Berrard S, Bejanin S, Mallet J (1994). Regulation by CDF/LIF and retinoic acid of multiple ChAT mRNAs produced from distinct promoters. J Neurorep 5: 1346-1348.

Cheng J-C, Patterson PH (1997). LIF is an autocrine factor for sympathetic neurons. Mol Cell Neurosci 9: 372-380.

Chesnokova V, Auernhammer CJ, Melmed S (1998). Murine leukemia inhibitory factor gene disruption attenuates the hypothalamo-pituitary-adrenal axis stress response. Endocrinology 139: 2209-2216.

Chesnokova V, Kariagina A, Melmed S (2002). Opposing effects of leukemia inhibitory factor and suppressor of cytokine signaling 3 on the ACTH axis response to inflammation. Am J Physiol Endocrinol Metab 282: E1110-E1118.

Chesnokova V, Melmed S (2000). Leukemia inhibitory factor mediates the hypothalamic pituitary adrenal axis response to inflammation. Endocrinology 141: 4032-4040.

Connor TJ, Leonard BE (1998). Depression, stress and immunological activation: the role of cytokines in depressive disorders. Life Sci 62: 583-606.

Cunningham Jr ET, De Souza EB (1993). Interleukin 1 receptors in the brain and endocrine tissues. Immunol Today 14: 171-176.

Dantzer R, Wollman E, Vitkovic L, Yirmiya R (1999). Cytokines and depression: fortuitous or causative association? $\mathrm{Mol}$ Psychiatry 4: 328-332.

Davidson RJ, Pizzagalli D, Nitschke JB, Putnam K (2002). Depression: perspectives from affective neuroscience. Ann Rev Psychol 53: 545-574.

Dawson GR, Tricklebank MD (1995). Use of the elevated plus maze in the search of novel anixolytic agents. Trends Pharmacol Sci 16: 33-36.

Dunn AJ, Wang J, Ando T (1999). Effects of cytokines on cerebral neurotransmission. Comparison with the effects of stress. $A d v$ Exp Med Biol 461: 117-127.

Gadient RA, Lein P, Higgins D, Patterson PH (1998). Effect of leukemia inhibitory factor (LIF) on the morphology and survival of cultured hippocampal neurons and glial cells. Brain Res 798: $140-146$

Gertsik L, Poland RE (2004). Psychoneuroendocrinology. In: Schatzberg A, Nemeroff CB (eds). Textbook of Psychopharmacology, 3rd edn. American Psychiatric Publishing: Arlington, VA. pp 115-129.
Hayley S, Brebner K, Lacosta S, Merali Z, Anisman H (1999). Sensitization to the effects of tumor necrosis factor-alpha: neuroendocrine, central monoamine, and behavioral variations. J Neurosci 19: 5654-5665.

Heyes MP, Saito K, Chen CY, Proescholdt MG, Nowak Jr TS, Li J et al (1997). Species heterogeneity between gerbils and rats: quinolinate production by microglia and astrocytes and accumulations in response to ischemic brain injury and systemic immune activation. J Neurochem 69: 1519-1529.

Kent S, Bluthe RM, Kelley KW, Dantzer R (1992). Sickness behavior as a new target for drug development. Trends Pharmacol Sci 13: 205-208.

Konsman JP, Parnet P, Dantzer R (2002). Cytokine-induced sickness behavior: mechanisms and implications. Trends Neurosci 25: 154-159.

Lemke R, Gadient RA, Schliebs R, Bigl V, Patterson PH (1996). Neuronal expression of leukemia inhibitory factor (LIF) in the rat brain. Neurosci Lett 13: 205-208.

Leonard BE (2001). The immune system, depression and the action of antidepressants. Prog Neuro-Psychopharmacol Biol Psychiat 25: 767-780.

Licinio J, Wong ML (1997). Pathways and mechanisms for cytocine signaling in the central nervous system. J Clin Invest 100: 29412947.

Licinio J, Wong ML (1999). The role of inflammatory mediators in the biology of major depression: central nervous system cytokines modulate the biological substrate of depressive symptoms, regulate stress-responsive systems, and contribute to neurotoxicity and neuroprotection. Mol Psychiatry 4: 317-327.

Maes M (1999). Major depression and activation of the inflammatory response system. Adv Exp Med Biol 461: 25-46.

Manji HK, Drevets WC, Charney DS (2001). The cellular neurobiology of depression. Nat Med 7: 541-547.

Miller AH (1998). Neuroendocrine and immune system interactions in stress and depression. Psychoneuroendocrinology 21: 443-463.

Mossner R, Lesch KP (1998). Role of serotonin in the immune system and in neuroimmune interactions. Brain Behav Immun 12: $249-271$

Nemeroff CB (1996). The corticotropin-releasing factor (CRF) hypothesis of depression: new findings and new directions. $\mathrm{Mol}$ Psychiatry 1: 336-342.

Porsolt RD, Bertin A, Jalfre M (1977a). Behavioral despair in mice: a primary screening test for antidepressants. Arch Int Pharmacodyn Ther 229: 327-336.

Porsolt RD, Le Pichon M, Jalfre M (1977b). Depression: a new animal model sensitive to antidepressant treatments. Nature 266: 730-732.

Ramamoorthy S, Ramamoorthy JD, Prasad PD, Bhat GK, Mahesh VB, Leibach FH et al (1995). Regulation of the human serotonin transporter by interleukin-1 beta. Biochem Biophys Res Commun 216: $560-567$.

Reichlin S (1999). Neuroendocrinology of infection and the innate immune system. Recent Prog Horm Res 54: 133-181.

Rudge JS, Eaton MJ, Mather P, Lindsay RM, Whitte RS (1996). CNTF induces raphe neuronal precursors to switch from a serotonergic to a cholinergic phenotype in vitro. Mol Cell Neurosci 7: 204-221.

Shintani F, Nakaki T, Kanba S, Sato K, Yagi G, Shiozawa M et al (1995). Involvement of interleukin-1 in immobilization stressinduced increase in plasma adrenocorticotropic hormone and in release of hypothalamic monoamines in the rat. J Neurosci 15: 1961-1970.

Shizuya K, Komori T, Fujiwara R, Miyahara S, Ohmori M, Nomura J (1998). The expressions of mRNAs for interleukin-6 (IL-6) and the IL- 6 receptor (IL-6R) in the rat hypothalamus and midbrain during restraint stress. Life Sci 62: 2315-2320. 
Stewart CL, Kaspar LJP, Brunet H, Bhatt I, Gadi I, Kontgen S et al (1992). Blastocytes implantation depends on maternal expression of leukemia inhibitory factor. Nature 359: 76-79.

Sugiura S, Lahav R, Han J, Kous S-Y, Banner L, de Pablo F et al (2000). Leukaemia inhibitory factor is required for normal inflammatory response to injury in the peripheral and central nervous systems in vivo and is chemotactic for macrophages in vitro. Eur J Neurosci 12: 457-466.

Suzuki E, Shintani F, Kanba S, Asai M, Nakaki T (1996). Induction of interleukin-1b and interleukin-1 receptor antagonist mRNA by chronic treatment with various psychotropics in widespread area of rat brain. Neurosci Letters 13: 201-204.

Turnbull AV, Rivier CL (1999). Regulation of the hypothalamicpituitary-adrenal axis by cytokines: actions and mechanisms of action. Physiol Rev: 79: 1-71.
Vitkovic L, Bockert J, Jacque C (2000). 'Inflammatory' cytokines: neuromodulators in normal brain? J Neurochem 74: 457-471.

Yamada K, Iida R, Miyamoto Y, Saito K, Sekikawa K, Seishma M et al (2000). Neurobehavioral alterations in mice with a targeted deletion of the tumor necrosis factor- $\alpha$ gene: implications for emotional behavior. J Neuroimmunol 111: 131-138.

Yirmiya R, Pollak Y, Morag M, Reichenberg A, Barak O, Avitsur R et al (2000). Illness, cytokines, and depression. Ann NY Acad Sci 917: 478-487.

Yirmiya R, Weidenfeld J, Pollak Y, Morgan M, Avitsur R, Barak O et al (1999). Cytokines, 'depression due to a general medical condition,' and antidepressant drugs. In: Dantzer et al (eds). Cytokines, Stress and Depression. Plenum: New York. pp 283-316.

Wichers M, Maes M (2002). The psychoneuroimmuno-pathophysiology of cytokine-induced depression in humans. Int $J$ Neuropsychopharmacol 5: 375-388. 